such a history was present the surgeon was advised that the level should not be taken as evidence of uncomplicated acute pancreatitis. In the remaining eight cases a correct diagnosis was made in six and laparotomy was performed on four (Cases 5, 8,9 , and 10 ), of which three survived and one died of a stroke; of the two not operated on, one (Case 12) was diagnosed as a mild uncomplicated afferent-loop obstruction and treated conservatively with success, while the other (Case 6) was considered unfit for operation and died. In the two remaining cases (Nos. 7 and 11) there was uncertainty about accepting this interpretation of the amylase level; in one there had been operative trauma to the pancreas, and both showed considerable initial improvement on intravenous fluids and antibiotics; operation was withheld, and both died of peritonitis.

We believe that correct interpretation of the amylase level would have led to operation in six patients who died, and might have reduced the overall mortality from eight to three.

Our interpretation of high amylase levels might have to be qualified if it were common for uncomplicated acute pancreatitis to occur after gastrectomy. We are not aware of such an occurrence in this hospital during the period under review. Warren (1951) described five cases, but in none was a plasmaamylase level of more than 1,000 units/ $100 \mathrm{ml}$. recorded, and in two there was perforation of the duodenal stump, supposedly the result of the pancreatitis ; in one other case (fatal) there was no confirmation of the diagnosis by laparotomy or necropsy. Dunphy et al. (1953) recorded three cases, but again none had a plasma-amylase level of over 1,000 units $/ 100 \mathrm{ml}$., and two were found at necropsy to have peritonitis in the absence of any obvious leak. Burton et al. (1957) described five cases, but the only one with a plasma-amylase level of more than 1,000 units/ $100 \mathrm{ml}$. was in fact suffering from biliary peritonitis due to perforation of the common bile-duct ; of the others, one had acute generalized peritonitis without any apparent leak. These published cases do not conflict with our thesis that a high plasma amylase after a gastrectomy is not likely to be due to uncomplicated acute pancreatitis.

The results in false positives without a history of gastrectomy were more favourable, because in 7 of the 10 cases the diagnosis of pancreatitis was not accepted on clinical grounds, and operations were performed with only one death. The three cases not operated on were one of perforated peptic ulcer, one of ruptured abdominal aortic aneurysm, and one of thrombosis of the superior mesenteric artery; all these patients died, but the second and third might well have died even with an operation.

\section{Summary and Conclusions}

We report a review of 113 patients with acute abdominal symptoms whose plasma-amylase level was more than 1,000 units (Somogyi) $/ 100 \mathrm{ml}$. Of these, $91(81 \%$ ) were suffering from conditions which did not require urgent surgery; 90 had acute pancreatitis, which was " primary" in 86.

The remaining $22(19 \%)$ patients were suffering from conditions which required urgent surgery, and just over half of this group had a history of gastrectomy. The complication of gastrectomy responsible for the patient's condition was usually afferent-loop obstruction, and perforation with generalized peritonitis was common; mortality was high if operation was not undertaken.

We conclude that whenever a high plasma-amylase level is found in association with an acute abdominal condition a history of gastrectomy should be sought. If it is present, the amylase level should be discounted as evidence of uncomplicated acute pancreatitis. Exclusion of these cases should considerably improve the practical value of plasma-amylase levels in the differential diagnosis of primary acute pancreatitis.

We are very grateful to the surgeons of the United Bristol Hospitals for permission to publish details of the patients admitted under their care.

\section{REFERENCES}

Ballon, H. C., and Niloff. P. H. (1959). Canad. med. Ass. F., 80, 339. Burton, C. C., Eckman, W. G., jun., and Haxo, J. (1957). Amer. F. Surg., 94, 70.

Dunphy, J. E., Brooks, J. R., and Ackroyd, F. (1953). New Engl. 7. Med., 248, 445 .

Hinshaw, D. B., Carter, R., Baker, H. W., and Wise, R. A. (1960). Ann. Surg., 151, 600 .

Howard, J. M. (1960). Surgical Diseases of the Pancreas, edited by J. M. Howard and G. L. Jordan. Pi man, London.

King, E. J. (1946). In Micro-Analysis in Medical Biochemistry. Churchill, London.

Millbourn, E.'(1949). Acta chir. scand., 98, 1.

Olson, C. A., Hinshaw, D. B., and Carter, R. (1960). Surg. Gynec. Obstet., 110, 66.

Perry, T., iun. (1954). Ann. Surg., 140, 119.

Somogyi, M. (1938). 7. biol. Chem., 125, 399.

Thal, A., and Perry, J. F., un. (1956). Ann. Surg., 143, 266.

Warren, K. W. (1951). Surgery, 29, 643.

\title{
Encephalitis Syndrome of Lymphocytic Choriomeningitis Virus Infection
}

\author{
K. K. NAYAK,* M.B., M.R.C.P. ; S. O. WALLER, † M.B., B.S., D.C.P. ; G. KUPPUSWAMY,
}

Rivers and Scott (1935) recovered the lymphocytic choriomeningitis (L.C.M.) virus from the cerebrospinal fluid of two patients with benign aseptic meningitis. The virus was so named because in experimental animals it produced inflammatory lesions of the choroid plexus.

L.C.M. virus is known to occur naturally in dogs, monkeys, guinea-pigs, and house mice, and has been isolated from nasal secretions, execretory and other material such as urine, faeces, and semen of animals (Adams, 1960).

Our knowledge of the natural history of infection with the L.C.M. virus in man is scanty. It is known to cause the syndrome of aseptic meningitis, fulfilling Wallgren's (1925) criteria; these are an acute onset of febrile illness with signs and symptoms of meningeal involvement, pleocytosis, and bacteriologically sterile cerebrospinal fluid. It is also recognized that it can cause a grippe-like illness in laboratory workers. Smadel et al. (1942) reported two fatal cases of infection with the L.C.M. virus in laboratory workers. During the illness both patients showed signs and symptoms of lower respiratory infection and patches of pneumonia were reported at necropsy. Lumbar puncture was not performed in either case during life as clinically there appeared to be no indication for it. L.C.M. virus was isolated from the blood and brain tissue in one case and from pulmonary tissue in the other.

\footnotetext{
Colonel, A.M.C. ; Professor of Medicine, Armed Forces Medical College,

2 Lieutenant-Colonel, A.M.C. ; Virologist and Associate Professor of Pathology, Armed Forces Medical College, Poona, India.

Surgeon Forcer Forces Medical College, Poona, India.
} 
The encephalitis syndrome occurring during infection with L.C.M. virus, however, is not well known, and a great deal needs to be learnt regarding the cerebral manifestations of this disease. With the object of adding to clinical knowledge of this condition we record three cases in which the encephalitis syndrome was observed during infection with the L.C.M. virus.

\section{Case 1}

A severe encephalitic illness, with coma and cerebrospinal fluid changes, in a 50-year-old male labourer ; complete recovery.

The patient had a head cold with fever, cough, and sore throat on 11 June 1962 but remained at work. On 14 June he fainted at work, and, when admitted to hospital soon after, was comatose, with a livid face. Temperature, pulse, and cardiovascular system showed no abnormality. The pupils were moderately dilated, were equal on both sides, and responded sluggishly to light; the kneeand ankle-jerks were sluggish, the abdominal reflexes were not clicited, and the plantar responses were flexor. The optic fundi were normal. He had no neck-stiffness and Kernig's sign was negative. There were no visible signs of head injury. Later the same day he answered a few simnle questions but remained quite oblivious of his surroundings. The next day he was drowsy but could be roused with difficulty. He was also very confused. On 16 June he remained stuporous but talked sensibly on being wakened, and drank fluids. He also co-operated with nursing staff in his toilet. From 17 June he behaved in a rational manner; convalescence was uneventful, and recovery complete.

Laboratory Investigations. - These showed the following abnormalíties: Total leucocyte count was $17,400 /$ c.mm. (neutrophils $87 \%$, tymphocytes $12 \%$, monocytes $1 \%$ ). Cerebrospinal fluid examination showed 3 lymphocytes on the date of admission; on 18 and 25 June there were no lymphocytes, but on 18 June protein had risen to $80 \mathrm{mg} . / 100 \mathrm{ml}$., and the fluid was positive for globulin. The complement-fixing antibody against the antigen of L.C.M. virus was positive in a dilution of 1 in 64 on two occasions (10 July and $20 \mathrm{July}$ ) and negative against antigens of other viruses.

\section{Case 2}

Encephalitic illness, involuntary movements, cerebrospinal fluid changes, and mental deterioration in a 25 -year-old male office clerk.

On 31 May 1962 the patient complained of a cold, with fever and cough. On 2 June he refused food and attempted to run away from the unit lines. Later he was found to be restless and confused. Irregular jerky movements of the eyes, head, and hands were observed on 8 June. He also wetted his trousers. He was sent to a hospital on 9 June for observation by a psychiatrist. Between 9 and 22 June he remained depressed, with inversion of the sleep rhythm. On examination on 23 June he was confused and disorientated. His thought processes were retarded and he had vague paranoid complaints about his unit. Clinical investigation showed no abnormality.

Laboratory Investigations.-Cerebrospinal fluid examination showed lymphocytes present on 26 and 30 June and 10 July. Protein was raised throughout and the fluid was positive for globulin. The complement-fixing antibody against the antigen of L.C.M. virus was positive in a dilution of 1 in 64 on two occasions (25 June and 10 July) and negative against antigens of other viruses. Total leucocyte count was $10,500 /$ c.mm. (neutrophils $72 \%$, eosinophils $6 \%$, lymphocytes $20 \%$, mononuclear cells $2 \%$ ). Other investigations, as in Case 1 , did not reveal any abnormality.

\section{Case 3}

Encephalitic illness, flaccid quadriparesis, absent cerebrospinal fluid changes, and complete recovery in a 40-year-old male follower.

He complained of " running nose," fever, cough, and a severe stitch-like pain in the right chest on 21 September 1962. The next morning he awoke feeling miserable and had a weary sensation in the legs. He went to the office and felt very weak and tired. Shortly afterwards he fainted. When he regained consciousness his friends sent him home at his own request in an ambulance. On 23 September he slept a great deal during the day as well as at night. He felt weaker and the weary sensation in the legs had increased. The next day he vomited five or six times and had severe headache.

On admission to hospital on 24 September his temperature was $100.4^{\circ} \mathrm{F}$. $\left(38^{\circ} \mathrm{C}\right.$.), pulse 110 , respirations 26 , and blood-pressure $110 / 70 \mathrm{~mm}$. Hg. His neck was not stiff and there were no abnormal signs in the cranial nerves. The pupils and the optic fundi were normal and there was no nystagmus. The deep reflexes were depressed and the plantar responses were flexor. The cardiovascular, respiratory, and alimentary systems were normal. Examination at this period showed that he was stuporous, the limbs were completely flaccid, the deep reflexes were profoundly depressed, and the plantars were extensor. During the next five days he was drowsy but could be wakened with a little difficulty. He regained consciousness on 29 September. Convalescence was uneventful and he made a complete recovery.

Laboratory Investigations. - The cerebrospinal fluid dynamics and composition were normal (24 September). Complementfixing antibody titre against the antigen of L.C.M. virus was positive in a dilution of 1 in 16 on 26 September and of 1 in 64 on 5 October. Total leucocyte count was $9,900 / \mathrm{c} . \mathrm{mm}$. (neutrophils $78 \%$, eosinophils $3 \%$, lymphocytes $18 \%$, monocytes $1 \%$ ). Other investigations, as in Cases 1 and 2 , did not show any abnormality.

\section{Discussion}

L.C.M. virus helongs to the viscerotrophic group of filterable viruses and is known to occur naturally in many species of animals. Cases have been recognized in various parts of the United States, the British Isles, Europe, and Asia. But, according to Adams (1960), very few proved cases of L.C.M. have been studied. We are not aware of any proved case of infection with the L.C.M. virus that has been reported from India so far. There is evidence that infection with the L.C.M. virus can cause the syndrome of aseptic meningitis and undifferentiated respiratory disease. Our patients had upper respiratory disease three days before the onset of the encephalitic illness, which was characterized by coma, pathological reflexes, mental deterioration, and ataxia. Diagnosis was established by demonstrating a fourfold rise in complementfixing antibody titre against the antigen of L.C.M. virus in convalescence. The cerebrospinal fluid showed an albuminocytological dissociation in Cases 1 and 2, the significance of which is difficult to explain. In Case 1 the fluid was normal at the beginning of the encephalitic illness; the protein content of the fluid rose at the end of the first week of the illness and decreased to normal in the third week. In Case 2 lumbar puncture was not performed in the first three weeks of the illness; the protein content of the fluid was increased in the fourth to sixth weeks and decreased to normal value in the seventh week of the illness. An entirely normal composition of the fluid in Case 3 is understandable because the fluid was examined once only, at the beginning of the illness.

Our patients received symptomatic treatment. Cases 1 and 3 made an early complete recovery. Mental deterioration in Case 2 necessitated psychotherapy, tranquillizers, and occupational therapy in order to rehabilitate him.

\section{Summary}

The literature on lymphocytic choriomeningitis (L.C.M.) virus has been reviewed. Three cases of encephalitis syndrome occurring during infection with the virus are presented. Diagnosis was based on a fourfold rise in the complement-fixing antibody titre against the antigen of L.C.M. virus. Two patients recovered fully and one patient showed mental deterioration.

We are indebted to Major-General T. R. Pahwa, Director of Medical Services (Army), for permission to make use of the hospital 
facilities. We thank Major-General P. N. Bardhan, Commandant, Armed Forces Medical College, Poona, for guidance, and LieutenantGeneral C. C. Kapila, Director General, Armed Forces Medical Services, for permission to publish this report. We also wish to thank Lieutenant-Colonel Karpal Singh and Major M. J. Chakravorthi for psychiatric assistance in rehabilitating one patient (Case 2).
REFERENCES

Adams, J. M. (1960). Neuer Virus Diseases, p. 171. Macmillan, New York

Rivers, T. M., and Scott, T. F. M. (1935). Science, 81, 439.

Smadel, J. E., Green, R. H., Paltauf, R. M., and Gonzales, T. A. (1942). Proc. Soc. exp. Biol. (N.Y.), 49, 683.

Wallgren, A. (1925). Cited in Cecil and Loeb's Textbook of Medicine, 10 th ed., p. 1492, edited by A. B. Gutman et al. Saunders, London.

\section{Medical Memoranda}

\section{Malignant Pericardial Effusion : a Case for Treatment}

\section{Brit. med. F., 1964, 1, 164}

The purpose of this communication is to note the uncommon condition of secondary malignant pericardial effusion, producing tamponade, arising from metastasizing carcinoma of the bladder, and to describe its treatment.

\section{Case Description}

A woman, aged 31 at the time of death, had a 19 months' history of haematuria with loss of weight and loin pain. Extensive carcinoma of the bladder having been demonstrated, radical total cystectomy was undertaken on 24 May 1962 with the removal of a right pyonephrosis. At this time hard glands extending beyond the aortic bifurcation were noted. A left ileal bladder was fashioned. Histology of the specimen showed squamous-cell carcinoma.

On 25 June she was readmitted because of loss of progress. Her only spontaneous complaint was of uriniferous vaginal discharge. She admitted to left chest pain, radiating to the neck and left shoulder. Marked dyspnoea was noted, with clinically clear lung fields. Seventy-two hours after admission the rising pulse rate was notable. The neck veins were bilaterally engorged to the jaw, and pulseless. The cardiac impulse was impalpable. Pulsus paradoxus was clearly demonstrated. The chest radiograph supported the diagnosis of pericardial effusion. The electrocardiogram showed ST elevation in the precordial leads, without $\mathrm{T}$-wave inversion, and in standard leads I and II. There was no evidence of myocardial infarction. Pericardial paracentesis, via the xiphisternal-subcostal route, revealed a grossly blood-stained fluid, with a haemoglobin concentration of 5.2 g. $/ 100 \mathrm{ml}$. and packed cell volume of $22.5 \%$; $200 \mathrm{ml}$. was removed, which afforded considerable subjective and objective relief. By the following day, however, the situation had recurred, and a similar amount of fluid was aspirated. In both specimens unequivocal malignant cells were demonstrated.

On 29 June, under local anaesthesia, by the same route, a " polythene " tube of $1 \mathrm{~mm}$. internal diameter was introduced into the pericardium with the aid of a trocar and cannula. Penicillin cover was instituted and maintained. The tube was left in situ, and drained up to $50 \mathrm{ml}$. of bloody fluid each 24 hours. $X$-radiotherapy was begun on 2 July, a course of five daily treatments to the mediastinum being applied through a single field 20 by $15 \mathrm{~cm}$. rectangular at $250 \mathrm{kV}$, half value layer $2 \mathrm{~mm}$. Cu, giving a dose of 2,000 rad maximum skin dose and 1,000 rad minimum tumour dose. With this the drainage diminished and ceased, so that it was possible to remove the catheter on 13 July. She was symptom-free in reference to her cardiovascular system, but an indwelling catheter was necessary to control the fistulous vaginal leak, and she was discharged home on 26 July. She was readmitted in extremis on 7 September 1962 and died 24 hours later.

Necropsy showed gross pyelonephritis in the remaining kidney, and widespread malignancy in the lymphatics, up to and including the mediastinal glands. The pericardial sac was obliterated by a loose fibrinous pericarditis, except for a small loculus at the apex which contained a few millilitres of bloody fluid. Microscopy of the pericardium showed viable cancer cells.

\section{Discussion}

Carcinomatous effusion of the pericardium is not a common complication of disseminated malignancy, except in those arising from breast and bronchus (Enticknap, 1952). Treatment in the present case was imperative because of the distress caused by the tamponade. The overall prognosis was obviously limited, but since the tamponade was the presenting symptomcomplex treatment of this was justifiable to gain time for a general surgical assessment. Treatment is not commonly mentioned in discussions of the condition because probably it is rarely of importance in the management of a terminally ill person with disseminated malignant disease. Radiotherapy and/or paracentesis of the pericardium is mentioned, "high voltage $x$-radiation may be of value ..." (Raven, 1948). Paracentesis seems to have been used only as an intermittent procedure, except the employment (Thurber et al., 1962) in one case of a pleuro-pericardial window after aspiration. On viewing our present case the effusion was producing an unpleasant life-threatening tamponade which demanded relief. Refilling and distress occurred with such rapidity that it was obvious that daily aspirations would be necessary. This would be unpleasant for the patient, and even if radiotherapy were to be a success some method of tiding over until its effect could be felt was obviously necessary. It was therefore agreed that radiotherapy should be undertaken, and the indwelling catheter used to cover the interim and the possibility of an exacerbation as a reaction to the radiotherapy.

My thanks are due to Mr. J. M. Ridley Thomas, under whose care this patient was admitted, for permission to record the facts ; and to Mr. W. J. L. Francis and Dr. A. L. M. Christie for permission to use their radiotherapy and post-mortem data respectively.

A. G. Hocken, M.B., B.S., Medical Registrar, Norfolk and Norwich Hospital.

REFERENCES

Enticknap, J. B. (1952). Guy's Hosp. Rep., 101, 273.

Raven, R. W. (1948). Brit. F. Cancer, 2, 1.

Thurber, D. L., Edwards, J. E., and Achor, R. P. W. (1962). Circulation. 26, 228. 